\title{
Rac1 signaling regulates LPS-induced mouse mastitis via inhibition of NLRP3, NF-KB and MAPK signaling pathways
}

\section{Chaoqun Wang}

Jilin University https://orcid.org/0000-0002-7186-6835

Aimin Jiang

Jilin University

Wang Jingjing

Jilin University

Xiao Liu

Jilin University

Han Zhen

Jilin University

Wei Zhengkai ( $\square$ wei_zhengkai@126.com )

Foshan University

Zhengtao Yang ( $\nabla$ yangzhengta001@sina.com )

Foshan University

\section{Research}

Keywords: Mastitis, Rac1, NSC23766, LPS, NF-KB

Posted Date: July 22nd, 2020

DOI: https://doi.org/10.21203/rs.3.rs-42322/v1

License: (c) (1) This work is licensed under a Creative Commons Attribution 4.0 International License. Read Full License 


\section{Abstract \\ Background}

Bovine mastitis characterized by mammary gland inflammatory responses, is the most frequent and costly diseases in dairy cattle. Researchers have been seeking effective treatments for this disease, but still not very successful. Ras-related C3 botulinum toxin substrate 1 (Rac1) is implicated in various cellular functions, including apoptosis, ROS production and inflammatory responses, and presents an attractive therapeutic target for many diseases. However, the effects of Rac1 signaling on mastitis remain unclear. The aim of this study is to investigate the effects of Rac1 signaling on mastitis via inhibition by Rac1 specific inhibitor NSC23766 based on a murine model of lipoplysaccharide (LPS)-induced mastitis.

\section{Methods}

Murine mastitis model was established by perfusion of LPS, hematoxylin-eosin (H \& E) staining was employed to explore the mechanisms in mouse model, qRT- PCR analysis, Western blotting analysis.

\section{Results}

The results revealed that NSC23766 significantly decreased the damage of mammary gland by LPS, reduced myeloperoxidase activities, and the productions of IL-1 $\beta$, IL-6, TNF- $\alpha$ and MCP-1 gene expression in the mammary glands with LPS perfusion. Moreover, western blot analysis showed that NSC23766 inhibited the phosphoryation of p65, IKBa, ERK, and p38, and suppressed the expression of NLRP3.

\section{Conclusion}

These findings suggested that administration of NSC23766 prevented the development of mastitis by inhibiting NLRP3, mitogen-activated protein kinase (MAPK) and nuclear factor-KB (NF-KB) signaling pathways. Accordingly, this study may provide research basis for the development of new drugs against mastitis, and NSC23766 might be a potential therapeutic drugs for mastitis.

\section{Background}

Bovine mastitis, an inflammatory response in the mammary gland, is one of the most costly pathologies in the dairy industry [1]. Milk yield and milk quality are influenced by this disease, and huge costs are paid on treatment and care, resulting more and more people paying attention on bovine mastitis. The main treatment for this disease is intramuscular or intravenous injection of antibiotics such as penicillin, streptomycin, and tetracycline. However, the excessive use of antibiotics contributes to the development of antibiotic-resistant pathogens. In large Chinese dairy herds, the prevalence of antimicrobial resistance 
in mastitis pathogens is comparatively high [2]. Thus, exploring alternatives to antibiotics in mastitis therapy is urgently needed.

Many pathogens are known to cause bovine mastitis, including bacteria, mycoplasma and yeasts [3]. The most common mastitis-causing bacteria includes Staphylococcus aureus and Escherichia coli [4], which invade the udder through the teat canal and cause a prompt inflammatory reaction [5].

Lipopolysaccharide (LPS) is a component of the outer membrane of gram-negative bacteria, and has been used to establish mouse model of mastitis [6]. LPS induces a potent inflammatory response in mammary tissue, which is similar to the natural mastitis. Pro-inflammatory cytokines including tumor necrosis factor alpha (TNF- $\alpha$ ), interleukin-6 (IL-6), and interleukin-1 $\beta$ (IL-1 $\beta$ ) are important in the development of LPS-induced mouse mastitis [7]. On the other hand, MAPK and NF-KB signaling pathways are known to regulate the expression of various pro-inflammatory genes, and play a crucial role in LPSinduced mouse mastitis [6]. Studies have revealed that mastitis are improved via inhibition of these two signaling pathways $[8,9]$.

Ras-related C3 botulinum toxin substrate 1 (Rac1) is a member of Rac family of small guanosine triphosphatases (GTPase), and is known to regulate various cellular functions, such as cell proliferation and survival, migration and invasion, cellular adhesions, apoptosis, ROS and inflammatory responses [10-13]. Deregulation of Rac1 signaling is invovled in a number of human diseases, indicating Rac1 is an attractive therapeutic target. The inhibition of Rac activity shows anti-inflammatory effects in models of acute pancreatitis and sepsis $[14,15]$. Targeting Rac1 decreases paw swelling in early arthritis and to a lesser extent in chronic arthritis in collagen-induced murine model of rheumatoid arthritis[16]. NSC23766 is a Rac-specific molecule inhibitor, and is often used to study the physiological functions of Rac1 [17]. Though previous study revealed that NSC23766 reduced the inflammatory cells infiltration and inhibited the expression of TNF- $\alpha$ and IL-1 $\beta$ [14], its detailed molecular mechanisms remain unknown. In this study, we aimed to investigate the effects and molecular mechanisms of NSC23766 in LPS-induced mastitis mice.

\section{Materials And Methods}

\section{Animals and LPS-induced mouse mastitis model}

BALB/c mice, 6-8 weeks old (18 female and 9 male), were divided into three groups, and each group contained two female and one male raised in a cage. After suckling mice born on the 10th day, 18 female

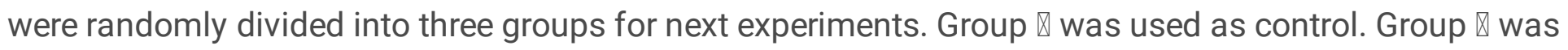
treated with LPS group. Group $\otimes$ treated with LPS and NSC23766 group. The method of establishment of mastitis mouse model refers to our previous reports [5]. In brief, the teat duct of Group \was infused with LPS $(200 \mu \mathrm{g} / \mathrm{mL})$. Group $\otimes$ mice were intraperitoneally injected with NSC23766 (5 mg/kg,

MedChemExpress) $1 \mathrm{~h}$ before LPS $(200 \mu \mathrm{g} / \mathrm{mL})$ treatment. Group $\otimes$ mice received an equal volume of PBS treatment. At $24 \mathrm{~h}$ after the LPS perfusion, mice were killed by $\mathrm{CO}_{2}$ inhalation. The mammary glands were collected and stored at $-80^{\circ} \mathrm{C}$ for later analysis. All animal experiments were in line with Jilin University 
experimental animal management regulations, and the People's Republic of China Animal Protection Law.

\section{Cell culture and treatments}

The mouse mammary epithelial cell line (EpH4-Ev) were cultured in DMEM medium F12 (Hyclone) supplemented with $10 \%$ fetal bovine serum (Clark) at $37^{\circ} \mathrm{C}$ with $5 \% \mathrm{CO}_{2}$. Cells plated into a 6-pore plate and pre-treated with NSC23766 (50, 100 and $200 \mu \mathrm{M})$ for 30 min. After that the cells were treated with LPS $(5 \mu \mathrm{g} / \mathrm{mL})$ for $12 \mathrm{~h}$, and collected for qRT-PCR and western blot analysis.

\section{Histopathological Examination}

The collected mammary tissues were fixed in $10 \%$ formalin for $48-72 \mathrm{~h}$. Then fixed mammary glands were dehydrated with graded alcohol, embedded in paraffin, and stained with hematoxylin and eosin (H\&E). Finally, the histopathologic changes were observed by light microscopy.

\section{Myeloperoxidase (MPO) Assay}

In order to detect the activity of MPO in the mammary glands, the collected mammary glands were homogenized, and detected by MPO kit (Jiancheng Bioengineering Institute of Nanjing). The specific experimental procedures were carried out according to the instruction.

\section{qRT- PCR Analysis}

Total RNA of mammary glands was extracted with Trizol (Invitrogen, USA), and complementary DNA (cDNA) was reversed transcription by the Revert Aid First Strand cDNA Synthesis Kit (Thermo Fisher Scientific, San Jose, CA). Primers were acquired from Sangon Biotech Co. Ltd (Shanghai, China, Table 1). The genes expressions of mammary glands were analyzed by using a 7500 real-time PCR system (Applied Biosystems, Carlsbad, CA, USA). The conditions were as follows: 2 min at $50{ }^{\circ} \mathrm{C}, 10 \mathrm{~min}$ at $95{ }^{\circ} \mathrm{C}$, followed by 40 cycles of $95^{\circ} \mathrm{C}$ for $15 \mathrm{~s}$ and $60^{\circ} \mathrm{C}$ for $1 \mathrm{~min}$.

\section{Western blotting}

Total protein in mammary tissue was extracted with the T-PER ${ }^{\mathrm{TM}}$ Tissue Protein Extraction Reagent (ThermoFisher, product number: 78510), which contains a propreitary detergent in $25 \mathrm{mM}$ bicine and 150 $\mathrm{mM}$ sodium chloride. Protein concentration was determined by BCA protein assay kit. The samples were separated by $10 \%$ SDS polyacrylamide gel, and then proteins were transferred to PVDF membranes. Membranes were blocked in $5 \%$ bovine serum albumin for $2 \mathrm{~h}$. Whereafter, the membranes were probed with primary antibody (1: 1000 dilution in TBST) overnight at $4{ }^{\circ} \mathrm{C}$, washed thrice in TBST with gentle mixing, and then incubated with peroxidase-conjugated secondary antibody (1: 20000 dilution in TBST) for $3 \mathrm{~h}$. After thrice washing in TBST, the samples were visualized with the ECLPlus Western Blotting Detection System (GE Healthcare, Chalfont St Giles, UK). Finally, the western blot bands were quantified by the software of ImageJ. The primary antibodies of ERK, P38, P65, Ikb, NLRP3 and GADPH were 
purchased from Boster bioengineering co. LTD (China).The primary antibodies of p-ERK (Thr202+Tyr204), p-p38 (Tyr182), p-p65 (ser536), p-ikb (S32/S36) were purchased from Bioworld Technology, Inc. (USA).

\section{Statistical analysis}

The data was analyzed by using GraphPad Prism 5.0 software. The western blot band intensities were quantified by the software of ImageJ. Difference among groups was analyzed by one-way analysis of variance (ANOVA) and the Tukey multiple comparison test. Values were expressed as the means the \pm standard deviation (SD). The significance threshold was set at 0.05 .

\section{Results}

\section{NSC23766 decreased LPS-induced pathologic changes in mastitis mice}

As shown in Fig 1, LPS significantly induced clinical symptoms of mastitis, such as slight swelling, displayed redness (Fig 1B) compared with control group (Fig 1A), but NSC23766 treatment (5 mg/kg) significantly decreased LPS-induced clinical symptoms of mastitis, which meant that NSC23766 possessed anti-inflammatory activities. To confirm the anti-inflammtory effects of NSC23766 on mastitis mice, histopathological examination was carried out. It was found that NSC 23766 also decreased LPSinduced pathologic changes including widened breast alveolar intervals, inflammatory cell infiltration and destruction of mammary acinar integrity (Fig 1D-1F), indicating its protective role in mastitis.

\section{NSC23766 decreased LPS-induced MPO activities}

Neutrophils are one of the first cells recruited to sites of inflammation, and MPO is the most abundantly expressed enzyme in neutrophil. Next, we examined main type of inflammatory cell infiltration in mammary gland. It was showed that LPS significantly increased MPO activities compared to the control group (Fig 2), but pretreatment with NSC23766 (5 mg/kg) abolished this increase of MPO activity induced by LPS (Fig 2), indicating that neutrophils are the main cell type infiltrated in mammary gland of mastitis.

\section{NSC23766 decreased LPS-induced cytokines and chemokines gene expression}

Given that cytokines and chemokines play crucial role in initiating inflammatory response, here we examined the effect of NSC23766 on expression of IL-1 $\beta$, IL-6, TNF- $\alpha$ and MCP-1 genes. As shown in Figure 3, IL-1 $\beta$, IL-6, TNF-a and MCP-1 mRNA levels in the LPS group was markedly increased compared with control group. However, NSC23766 (5 mg/kg) pre-treatment also significantly decreased LPSinduced IL-1 $\beta$, IL-6, TNF- $\alpha$ and MCP-1 mRNA levels in mammary glands of mastitis mice, implying that NSC23766 also plays a role in regulating these gene expression of IL-1 $\beta$, IL-6, TNF- $a$ and MCP-1 in mastitis.

NSC23766 inhibited LPS-induced the key proteins activities of NLRP3, MAPK, and NF-KB signaling pathways in mastitis 
To examine how NSC23766 regulated the gene expression of proinflammatory cytokines, we investigated several signaling pathways (NLRP3, MAPK, and NF-KB) involved in inflammation. Our results revealed that NLRP3 expression in the mammary tissues was dramatically increased by LPS perfusion compared to that of control group (Fig 4). Moreover, LPS resulted in significant phosphorylation of ERK and p38 in MAPK signaling pawthway (Fig 5), p65 and IKBa in NF-KB signaling pawthway (Fig 6). However, pretreatment with NSC23766 significantly inhibited the activities of NLRP3 and reduced phosphorylation of p65, ІкBa, ERK, and p38 suggesting an important role of NSC23766 in regulating these signaling pathway to prevent LPS-induced inflammatory responses.

For further confirm the crucial role of NSC23766 in protecting LPS-induced inflammatory response in mastitis, mammary gland cells lines were used for next investigation. The results showed that LPS not only increased the expressions of IL-1a, IL-1 $\beta$, IL-6, TNF- $\alpha$ and MCP-1 mRNA levels (Fig 7), but also induced the phosphorylation of p65 and IкBa in NF-KB signaling pathway (Fig 8). Surely, pretreatment with NSC23766 decreased LPS-induced these inflammatory response (Fig 7 and Fig 8). All above results suggest the key role of Rac1 signaling pathway in LPS-induced mastitis.

\section{Discussion}

Bovine mastitis, an inflammatory response of the mammary gland, is quite common in dairy cows [18]. Until now, mastitis still is a major challenge to the worldwide dairy industry. On the one hand, mastitis declines the production and quality of milk, which causes great economic losses [3]. On the other hand, mastitis can affect the fertility of cows [19]. For these reasons, it is crucial to find an effective treatment program for mastitis.

Rac1 is one of Rho small GTPases, which is an important component in inflammatory reponse [20], and NSC23766 as a Rac-specific inhibitor, exhibits significant anti-inflammatory effects in animal models of many diseases, such as acute pulmonary injury, colonic injury and septic lung injury [21-23]. In this study, we aimed to investigate the effects of NSC23766 on LPS-induced mastitis, and further explored its fundamental mechanisms.

Increasing publications suggest that Rac 1 plays a significant role in inflammatory reactions. Rac 1 has special research value in the present study since data in the literature show that Rac1 regulates the progression of the inflammatory response, such as acute lung injury [24]. It was found that inhibition of Rac 1 activity with NSC23766 significantly weakened LPS-induced pathologic changes such as decreasing inflammatory cell infiltration, widened breast alveolar intervals and destruction of mammary acinar integrity. Moreover, we confirmed that inhibition of Rac 1 activity reduced MPO activity in mammary gland of mastitis, which is consistent with our previous research on the anti-inflammatory effects of baicalein [8]. MPO, a marker of neutrophil function and activation, is related to the neutrophil infiltration into the tissue and directly proportional to the number of neutrophils in the tissue [25]. Collectively, these results suggest that NSC23766 prevented LPS-induced inflammatory damage via suppressing neutrophil infiltration. 
Cytokines are involved in the regulation of many local inflammations and systemic inflammation [26]. IL$1 \beta$, IL-6, TNF- $\alpha$ and MCP-1 are the most common cytokines and chemokines in several inflammatory reactions. To further investigate the protective role of NSC23766 in LPS-induced mastitis, the gene expression of IL-1 $\beta$, IL- 6 , TNF- $a$ and MCP-1 was measured. Compared with the LPS group, the levels of IL$1 \beta$, IL-6, TNF- $\alpha$ and MCP-1 in mammary gland were reduced by NSC23766 pretreatment. These results suggested that NSC23766 did attenuate the inflammatory reactions in LPS-induced mastitis, suggesting the important role of Rac1 signaling pawthway in mastitis.

Although we found that Rac1 is involved in LPS-induced mastitis, the signaling pathways in this process are still unclear. NLRP3, a component of the inflammasome, is composed of the NLRP3, ASC and caspase-1 $[27,28]$. Once NLRP3 inflammasome activated, it can convert the inactive pro-IL-1 $\beta$ to a biologically active form [29]. IL-1 $\beta$ is a pro-inflammatory cytokine which is the most important of all cytokines in the inflammatory process [30]. Moreover, the activation of NF-KB and MAPK signaling pathways are partly resulting in the activation of NLRP3 inflammasome [31]. In this study, it was found that NSC23766 significantly reduced LPS-induced the expression of NLRP3, indicating that NSC23766 inhibited pro-inflammatory cytokine IL-1 $\beta$ expression partly via inflammasome formation. Rac1 is a key mediator in a variety of cellular events, including ROS generation, chemotaxis, cytoskeleton remodeling and gene transcription [32]. It has been reported Rac 1 activates p38 MAPK signaling pathway via the p21 activated kinase 1 (PAK1) [33]. Moreover, MAPK signaling pathway activation increases pro-inflammatory cytokines secretions, which regulate the inflammatory response [34]. Our data indicated that NSC23766 pre-treatment significantly reduced ERK and p38 phosphorylation levels in mouse mammary gland, which is consistent with previous study. Since NSC23766 inhibits the MAPK pathway, we subsequently examined other more signaling pathways which are involved in the inflammatory response of mastitis. $\mathrm{NF}-\mathrm{kB}$, a main regulatory transcription factor, plays a crucial role in immune responses, such as the regulation of genes encoding pro-inflammatory cytokines [35]. Reports have shown that multiple drugs exhibit anti-inflammatory effects by inhibiting the NF-KB signaling pathway, such as cepharanthine, baicalein and morin $[5,8,36]$. Moreover, Rac 1 is closely related to NF-KB signaling pathway, which regulates the degradation of IKBa and nuclear translocation of STAT3-NF-KB complexes in starved cancer cells $[37,38]$. The results revealed that NSC23766 significantly inhibited the activation of p65 and degradation of IKBa in mouse mammary gland. These data indicated that NSC23766 exerted its antiinflammatory effects by inhibiting the activation of NLRP3, NF-KB and MAPK signaling pathways.

\section{Conclusions}

In summary, our work demonstrated the effects of NSC23766 as an inhibitor of Rac 1 in regulating LPSinduced mastitis in mice. Pretreatment with NSC23766 protected mammary gland from LPS-induced inflammatory responses via inhibiting the activation of NLRP3, NF-KB and MAPK signal pathways, implying an important role of Rac 1 signaling in regulating these processes. All data suggest that Rac 1 is a key regulator in LPS-induced mastitis and provide a new understanding the role of Rac1 in the inflammatory responses process. Nevertheless, other more potential molecular mechanisms that may regulate LPS-induced mastitis in mice need to be further explored. 


\section{Abbreviations}

LPS: lipoplysaccharide; MAPK: mitogen-activated protein kinase; NF-кB: nuclear factor-kB; NLRP3: NOD-, LRR- and pyrin domain-containing 3; Rac1: Ras-related C3 botulinum toxin substrate 1.

\section{Declarations}

\section{Acknowledgements}

Not applicable.

\section{Funding}

This work was funded by the National Natural Science Foundation of China (No. 31772721).

\section{Availability of data and materials}

Please contact corresponding author for data requests.

\section{Authors' contributions}

$\mathrm{CW}$ wrote the paper and performed the experiments; AJ and WJ performed the experiments; $\mathrm{XL}$ and $\mathrm{ZH}$ analyzed the data; ZY and ZW contributed to design the experiments. All authors read and approved the final manuscript.

\section{Ethics approval and consent to participate}

All animal experiments were in line with Jilin University experimental animal management regulations, and the People's Republic of China Animal Protection Law.

\section{Consent for publication}

All authors have read the manuscript and approved the final version.

\section{Competing interests}

The authors declare that they have no competing interests.

\section{Author details}

${ }^{a}$ College of Life Sciences and Engineering, Foshan University, Foshan 528225, Guangdong Province, PR China;

${ }^{b}$ Key Laboratory of Zoonosis, Ministry of Education, College of Veterinary Medicine, Jilin University, Changchun 130062, Jilin province, PR China; 


\section{References}

1. Gomes F, Saavedra MJ, Henriques M. Bovine mastitis disease/pathogenicity: evidence of the potential role of microbial biofilms. Pathog Dis 2016, 74.

2. Cheng J, Qu W, Barkema HW, Nobrega DB, Gao J, Liu G, De Buck J, Kastelic JP, Sun H, Han B. Antimicrobial resistance profiles of 5 common bovine mastitis pathogens in large Chinese dairy herds. J Dairy Sci. 2019;102:2416-26.

3. Ruegg PL. A 100-Year Review: Mastitis detection, management, and prevention. J Dairy Sci. 2017;100:10381-97.

4. Blum SE, Heller ED, Jacoby S, Krifucks O, Leitner G. Comparison of the immune responses associated with experimental bovine mastitis caused by different strains of Escherichia coli. J Dairy Res. 2017;84:190-7.

5. Ershun Z, Yunhe F, Zhengkai W, Yongguo C, Naisheng Z, Zhengtao Y. Cepharanthine attenuates lipopolysaccharide-induced mice mastitis by suppressing the NF-kappaB signaling pathway. Inflammation. 2014;37:331-7.

6. Wei W, Dejie L, Xiaojing S, Tiancheng W, Yongguo C, Zhengtao Y, Naisheng Z. Magnolol inhibits the inflammatory response in mouse mammary epithelial cells and a mouse mastitis model. Inflammation. 2015;38:16-26.

7. Jiang K, Ma X, Guo S, Zhang T, Zhao G, Wu H, Wang X, Deng G. Anti-inflammatory Effects of Rosmarinic Acid in Lipopolysaccharide-Induced Mastitis in Mice. Inflammation. 2018;41:437-48.

8. He X, Wei Z, Zhou E, Chen L, Kou J, Wang J, Yang Z. Baicalein attenuates inflammatory responses by suppressing TLR4 mediated NF-kappaB and MAPK signaling pathways in LPS-induced mastitis in mice. Int Immunopharmacol. 2015;28:470-6.

9. Yang Z, Yin R, Cong Y, Yang Z, Zhou E, Wei Z, Liu Z, Cao Y, Zhang N. Oxymatrine lightened the inflammatory response of LPS-induced mastitis in mice through affecting NF-kappaB and MAPKs signaling pathways. Inflammation. 2014;37:2047-55.

10. Wells CM, Walmsley M, Ooi S, Tybulewicz V, Ridley AJ. Rac1-deficient macrophages exhibit defects in cell spreading and membrane ruffling but not migration. J Cell Sci. 2004;117:1259-68.

11. Barros P, Jordan P, Matos P. Rac1 signaling modulates BCL-6-mediated repression of gene transcription. Mol Cell Biol. 2009;29:4156-66.

12. Hall A. Rho GTPases and the control of cell behaviour. Biochem Soc Trans. 2005;33:891-5.

13. Etienne-Manneville S, Hall A. Rho GTPases in cell biology. Nature. 2002;420:629-35.

14. Jiang JX, Zhang SJ, Shen HJ, Guan Y, Liu Q, Zhao W, Jia YL, Shen J, Yan XF, Xie QM. Rac1 signaling regulates cigarette smoke-induced inflammation in the lung via the Erk1/2 MAPK and STAT3 pathways. Biochim Biophys Acta Mol Basis Dis. 2017;1863:1778-88.

15. Arnst JL, Hein AL, Taylor MA, Palermo NY, Contreras JI, Sonawane YA, Wahl AO, Ouellette MM, Natarajan A, Yan Y. Discovery and characterization of small molecule Rac1 inhibitors. Oncotarget. 2017;8:34586-600. 
16. Abreu JR, Dontje W, Krausz S, de Launay D, van Hennik PB, van Stalborch AM, Ten Klooster JP, Sanders ME, Reedquist KA, Vervoordeldonk MJ, et al. A Rac1 inhibitory peptide suppresses antibody production and paw swelling in the murine collagen-induced arthritis model of rheumatoid arthritis. Arthritis Res Ther. 2010;12:R2.

17. Hou H, Chavez AE, Wang CC, Yang H, Gu H, Siddoway BA, Hall BJ, Castillo PE, Xia H. The Rac1 inhibitor NSC23766 suppresses CREB signaling by targeting NMDA receptor function. J Neurosci. 2014;34:14006-12.

18. Mushtaq S, Shah AM, Shah A, Lone SA, Hussain A, Hassan QP, Ali MN. Bovine mastitis: An appraisal of its alternative herbal cure. Microb Pathog. 2018;114:357-61.

19. van Knegsel AT, van der Drift SG, Cermakova J, Kemp B. Effects of shortening the dry period of dairy cows on milk production, energy balance, health, and fertility: a systematic review. Vet J. 2013;198:707-13.

20. Pan D, Amison RT, Riffo-Vasquez Y, Spina D, Cleary SJ, Wakelam MJ, Page CP, Pitchford SC, Welch HC. P-Rex and Vav Rac-GEFs in platelets control leukocyte recruitment to sites of inflammation. Blood. 2015;125:1146-58.

21. Yao HY, Chen L, Xu C, Wang J, Chen J, Xie QM, Wu X, Yan XF. Inhibition of Rac activity alleviates lipopolysaccharide-induced acute pulmonary injury in mice. Biochim Biophys Acta. 2011;1810:66674.

22. Zheng XB, Liu HS, Zhang LJ, Liu XH, Zhong XL, Zhou C, Hu T, Wu XR, Hu JC, Lian L, et al. Engulfment and Cell Motility Protein 1 Protects Against DSS-induced Colonic Injury in Mice via Rac1 Activation. J Crohns Colitis. 2019;13:100-14.

23. Hwaiz R, Rahman M, Syk I, Zhang E, Thorlacius H. Rac1-dependent secretion of platelet-derived CCL5 regulates neutrophil recruitment via activation of alveolar macrophages in septic lung injury. $J$ Leukoc Biol. 2015;97:975-84.

24. Binker MG, Binker-Cosen AA, Gaisano HY, Cosen-Binker LI. Inhibition of Rac1 decreases the severity of pancreatitis and pancreatitis-associated lung injury in mice. Exp Physiol. 2008;93:1091-103.

25. Hayashi T, Ago K, Ago M, Yamanouchi H, Bunai Y, Ogata M. The infiltration of 'primed' neutrophils into multiple organs due to physical abuse to the elderly: An immunohistochemical study. Forensic Sci Int. 2010;202:17-25.

26. Henaut L, Sanchez-Nino MD, Aldamiz-Echevarria Castillo G, Sanz AB, Ortiz A. Targeting local vascular and systemic consequences of inflammation on vascular and cardiac valve calcification. Expert Opin Ther Targets. 2016;20:89-105.

27. Liu SB, Mi WL, Wang YQ. Research progress on the NLRP3 inflammasome and its role in the central nervous system. Neurosci Bull. 2013;29:779-87.

28. Wei Z, Wang J, Wang Y, Wang C, Liu X, Han Z, Fu Y, Yang Z. Effects of Neutrophil Extracellular Traps on Bovine Mammary Epithelial Cells in vitro. Front Immunol. 2019;10:1003.

29. Duong BH, Onizawa M, Oses-Prieto JA, Advincula R, Burlingame A, Malynn BA, Ma A. A20 restricts ubiquitination of pro-interleukin-1beta protein complexes and suppresses NLRP3 inflammasome 
activity. Immunity. 2015;42:55-67.

30. Di Paolo NC, Shayakhmetov DM. Interleukin 1alpha and the inflammatory process. Nat Immunol. 2016;17:906-13.

31. Budai MM, Varga A, Milesz S, Tozser J, Benko S. Aloe vera downregulates LPS-induced inflammatory cytokine production and expression of NLRP3 inflammasome in human macrophages. Mol Immunol. 2013;56:471-9.

32. Maitra U, Singh N, Gan L, Ringwood L, Li L. IRAK-1 contributes to lipopolysaccharide-induced reactive oxygen species generation in macrophages by inducing NOX-1 transcription and Rac1 activation and suppressing the expression of antioxidative enzymes. J Biol Chem. 2009;284:35403-11.

33. Grill B, Schrader JW. Activation of Rac-1, Rac-2, and Cdc42 by hemopoietic growth factors or crosslinking of the B-lymphocyte receptor for antigen. Blood. 2002;100:3183-92.

34. Patraca I, Martinez N, Busquets O, Marti A, Pedros I, Beas-Zarate C, Marin M, Ettcheto M, Sureda F, Auladell C, et al. Anti-inflammatory role of Leptin in glial cells through p38 MAPK pathway inhibition. Pharmacol Rep. 2017;69:409-18.

35. Feng C, He J, Zhang Y, Lan M, Yang M, Liu H, Huang B, Pan Y, Zhou Y. Collagen-derived N-acetylated proline-glycine-proline upregulates the expression of pro-inflammatory cytokines and extracellular matrix proteases in nucleus pulposus cells via the NF-kappaB and MAPK signaling pathways. Int $\mathrm{J}$ Mol Med. 2017;40:164-74.

36. Wei Z, He X, Kou J, Wang J, Chen L, Yao M, Zhou E, Fu Y, Guo C, Yang Z. Renoprotective mechanisms of morin in cisplatin-induced kidney injury. Int Immunopharmacol. 2015;28:500-6.

37. Cuadrado A, Martin-Moldes Z, Ye J, Lastres-Becker I. Transcription factors NRF2 and NF-kappaB are coordinated effectors of the Rho family, GTP-binding protein RAC1 during inflammation. J Biol Chem. 2014;289:15244-58.

38. Yao C, Yu KP, Philbrick W, Sun BH, Simpson C, Zhang C, Insogna K. Breast cancer-associated gene 3 interacts with Rac1 and augments NF-kappaB signaling in vitro, but has no effect on RANKL-induced bone resorption in vivo. Int J Mol Med. 2017;40:1067-77.

\section{Tables}

Table. 1. Primers used in this study 


\begin{tabular}{|c|c|c|c|}
\hline Gene & Primer & Sequence $5^{\prime}>3^{\prime}$ & Size (bp) \\
\hline \multirow[t]{2}{*}{ TNF- $\alpha$} & Sense & ACGGCATGGATCTCAAAGAC & 116 \\
\hline & Anti-sense & GTGGGTGAGGAGCACGTAGT & \\
\hline \multirow[t]{2}{*}{ IL-1 $\beta$} & Sense & GCTGCTTCCAAACCTTTGAC & 121 \\
\hline & Anti-sense & AGCTTCTCCACAGCCACAAT & \\
\hline \multirow[t]{2}{*}{ IL-6 } & Sense & CCGGAGAGGAGACTTCACAG & 134 \\
\hline & Anti-sense & CAGAATTGCCATTGCACAAC & \\
\hline \multirow[t]{2}{*}{ GAPDH } & Sense & TGCTGTCCCTGTATGCCTCT & 224 \\
\hline & Anti-sense & TTTGATGTCACGCACGATT & \\
\hline \multirow[t]{2}{*}{ MCP1 } & Sence & CCACTCACCTGCTGCTACTCATTC & 83 \\
\hline & Anti-sense & CTGCTGCTGGTGATCCTCTTGTAG & \\
\hline \multirow[t]{2}{*}{ IL-1 $\alpha$} & Sence & CAGTATCAGCAACGTCAAGCAACG & 190 \\
\hline & Anti-se & sse AACTTCTGCCTGACGAGCTTCATC & \\
\hline
\end{tabular}

\section{Figures}
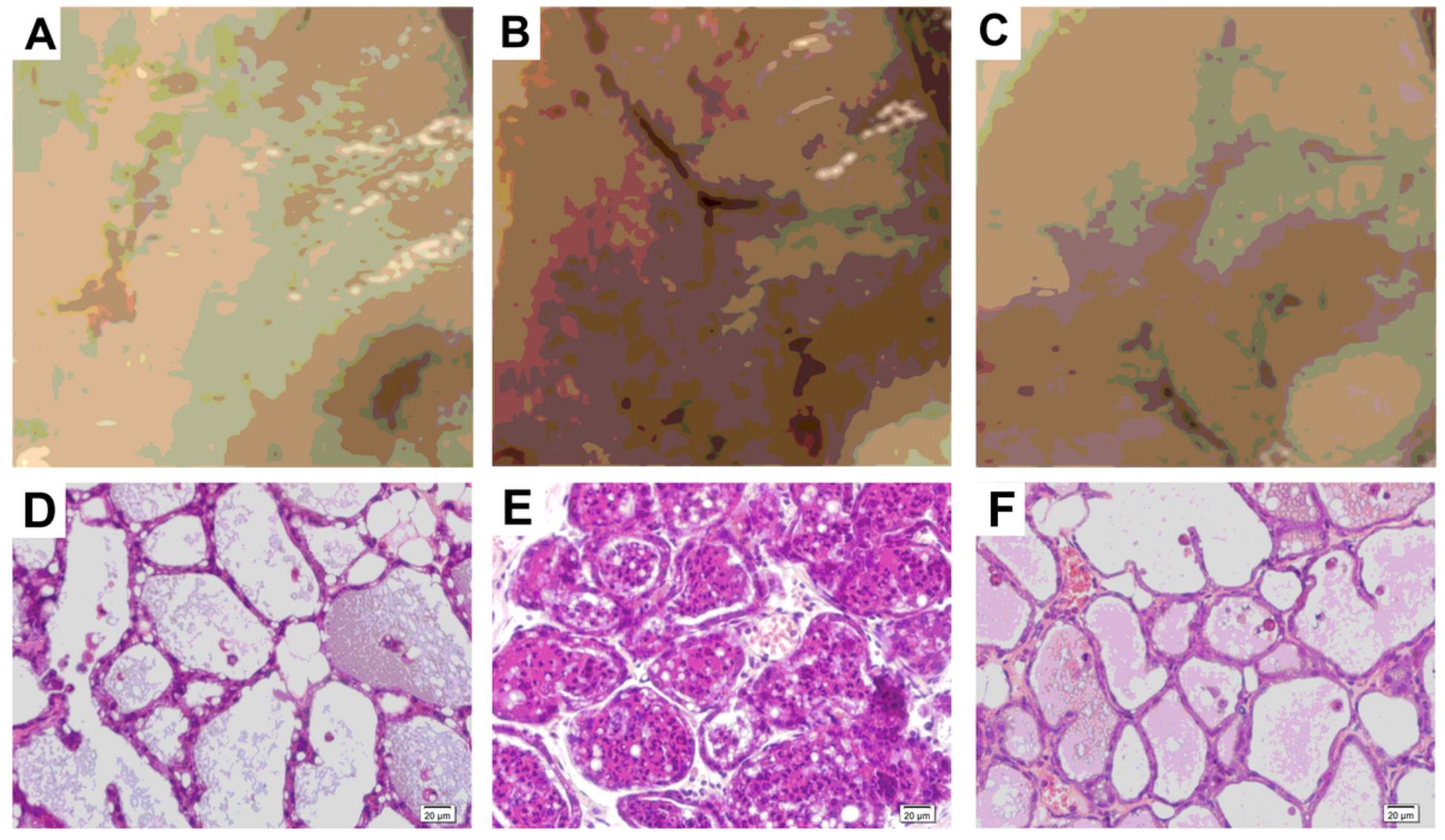

\section{Figure 1}

NSC23766 decreased LPS-induced clinical symptoms and histopathologic changes in mammary glands of mastitis. (A) Observation of control group. (B) Observation of LPS group showed slight swelling, displayed redness in mastitis. (C) Observation of LPS + NSC23766 group that NSC23766 decreased LPSinduced clinical symptoms in mammary glands of mastitis. (D) Histopathological examination of control group ( $\times 400)$. (E) Histopathological examination of LPS group showed inflammatory cell infiltration, widened breast alveolar intervals and destruction of mammary acinar integrity $(\times 400)$. $(F)$ 
Histopathological examination of LPS + NSC23766 group showed that NSC23766 decreased LPSinduced histopathologic changes in mammary glands of mastitis $(\times 400)$.

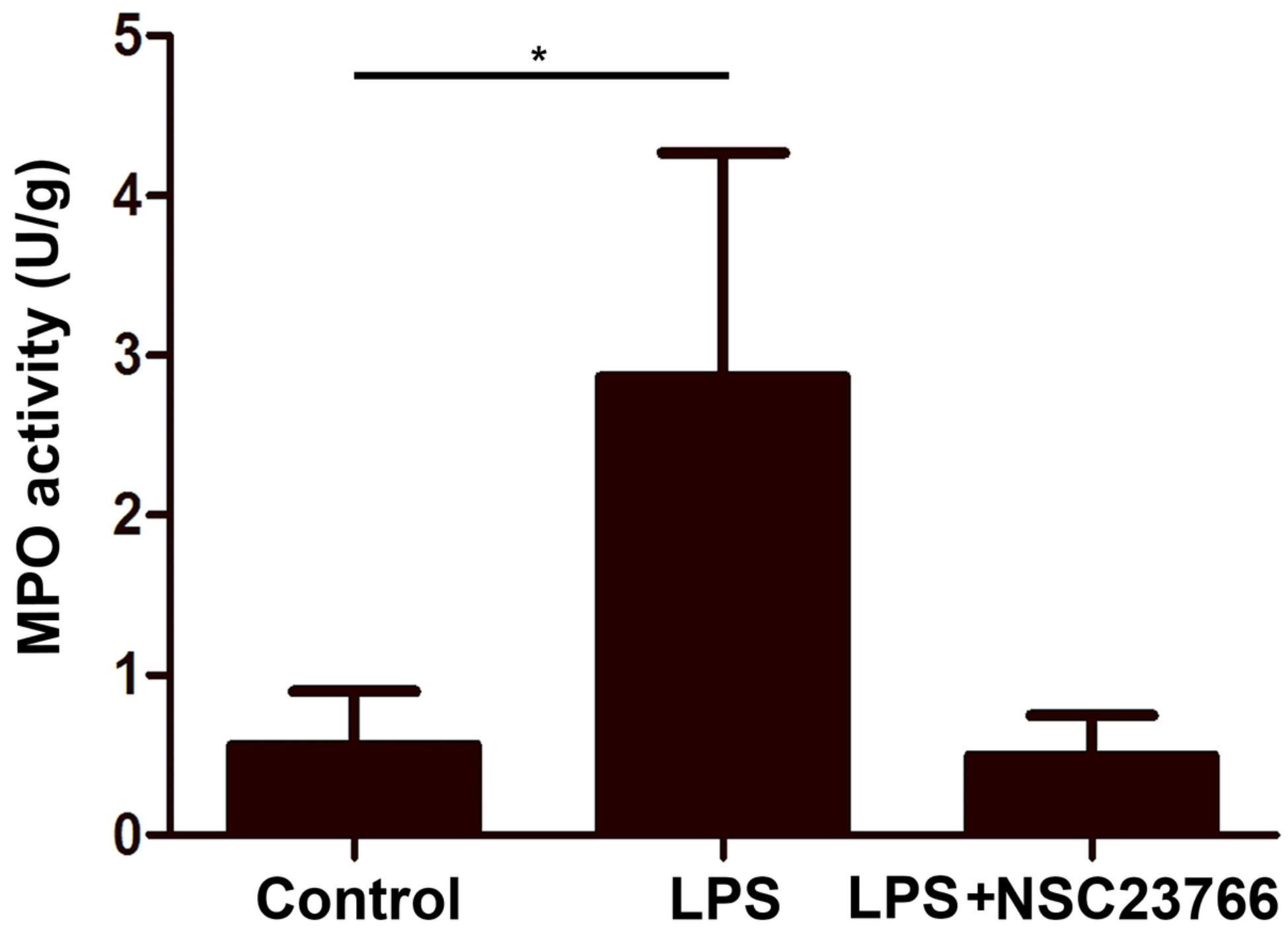

Figure 2

NSC23766 decreased LPS-induced MPO activities. NSC23766 was administered intraperitoneally $1 \mathrm{~h}$ prior to LPS-induced mastitis model. MPO activities in mammary gland were measured by the corresponding kit. The results showed that NSC23766 $(5 \mathrm{mg} / \mathrm{kg})$ abolished LPS-induced MPO activity in mammary glands of mastitis. The date is presented as mean $\pm S D(n=5)$. P values of $<0.05$ were considered significant. (*means $\mathrm{P}<0.05)$. 

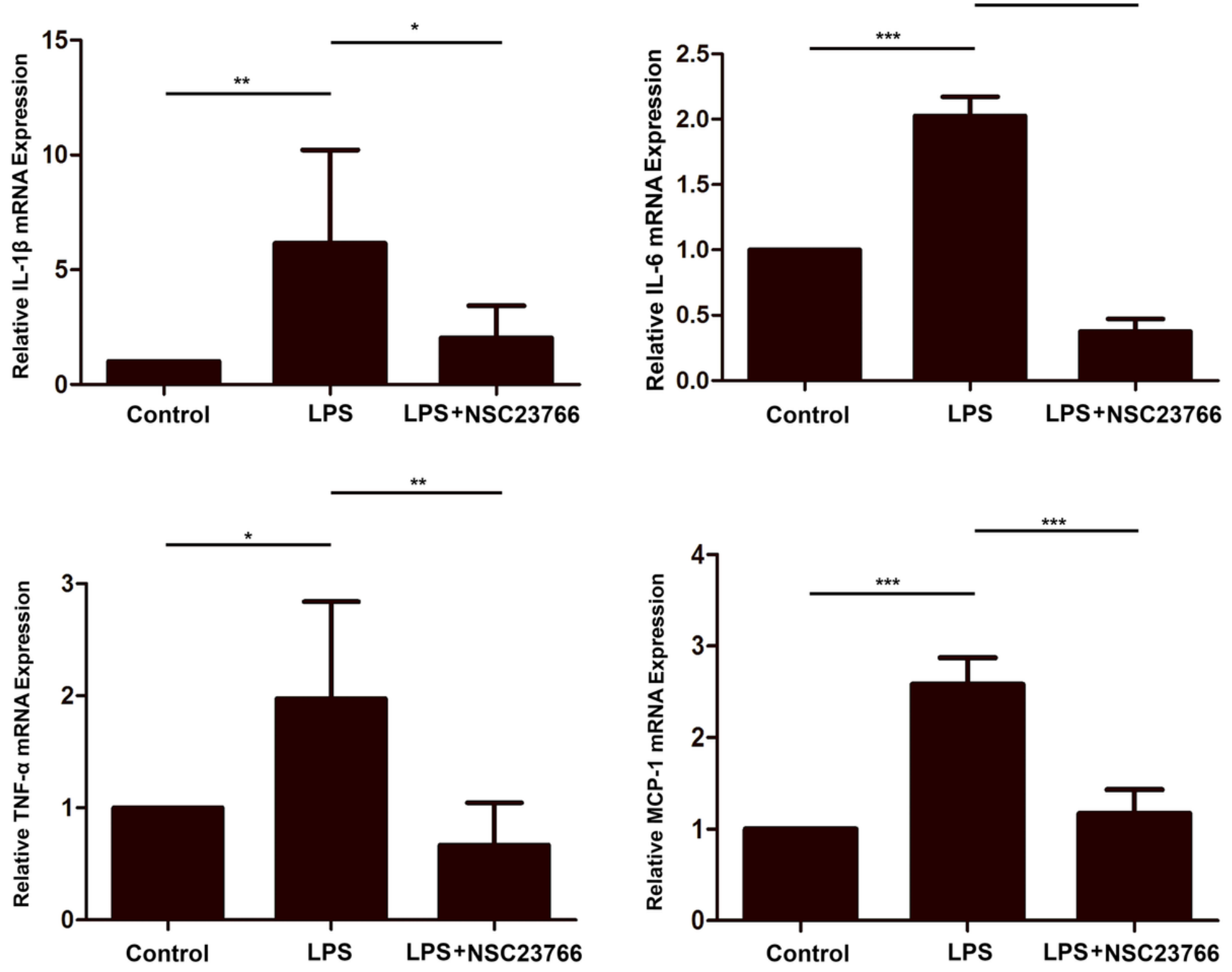

Figure 3

NSC23766 decreased the mRNA levels of IL-1 $\beta$, IL-6, TNF- $\alpha$ and MCP-1 in the LPS-induced mouse mastitis. The mRNA levels of IL-1 $\beta$, IL- -6 , TNF- $\alpha$ and MCP- 1 was measured by qRT-PCR. The data was presented as mean $\pm S D(n=5)$. P values of $<0.05$ were considered significant. (*means $P<0.05$, ** means $\mathrm{P}<0.01$ and ${ }^{* *}$ means $\left.\mathrm{P}<0.001\right)$. 
GAPDH

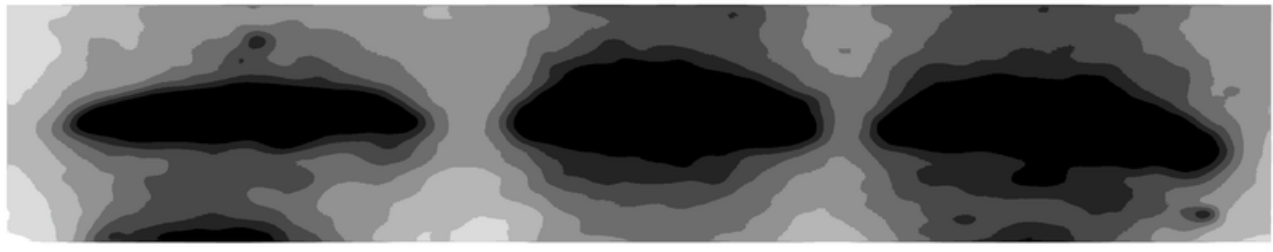

\section{$36 \mathrm{kDa}$}

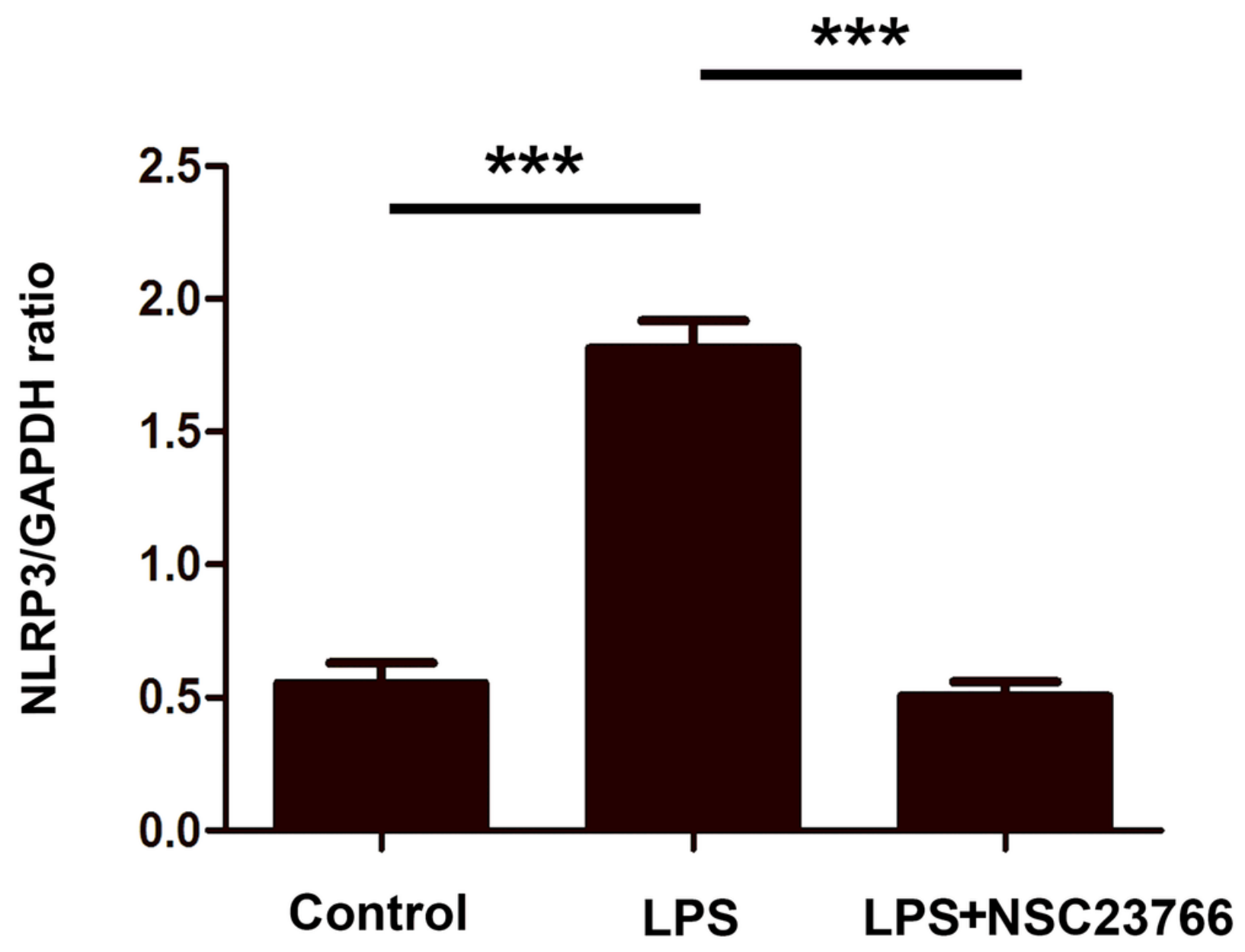

Figure 4

NSC23766 inhibited LPS-induced activities of NLRP3 signaling pathways in mastitis. Western blot analysis was performed for examining NLRP3 activities in mouse mammary gland. The results showed that NSC23766 significantly inhibited the activities of NLRP3 signaling pathways. The date is presented as mean $\pm \operatorname{SD}(n=5)$. $P$ values of $<0.05$ were considered significant. $\left({ }^{\star *}\right.$ means $\left.P<0.001\right)$. 


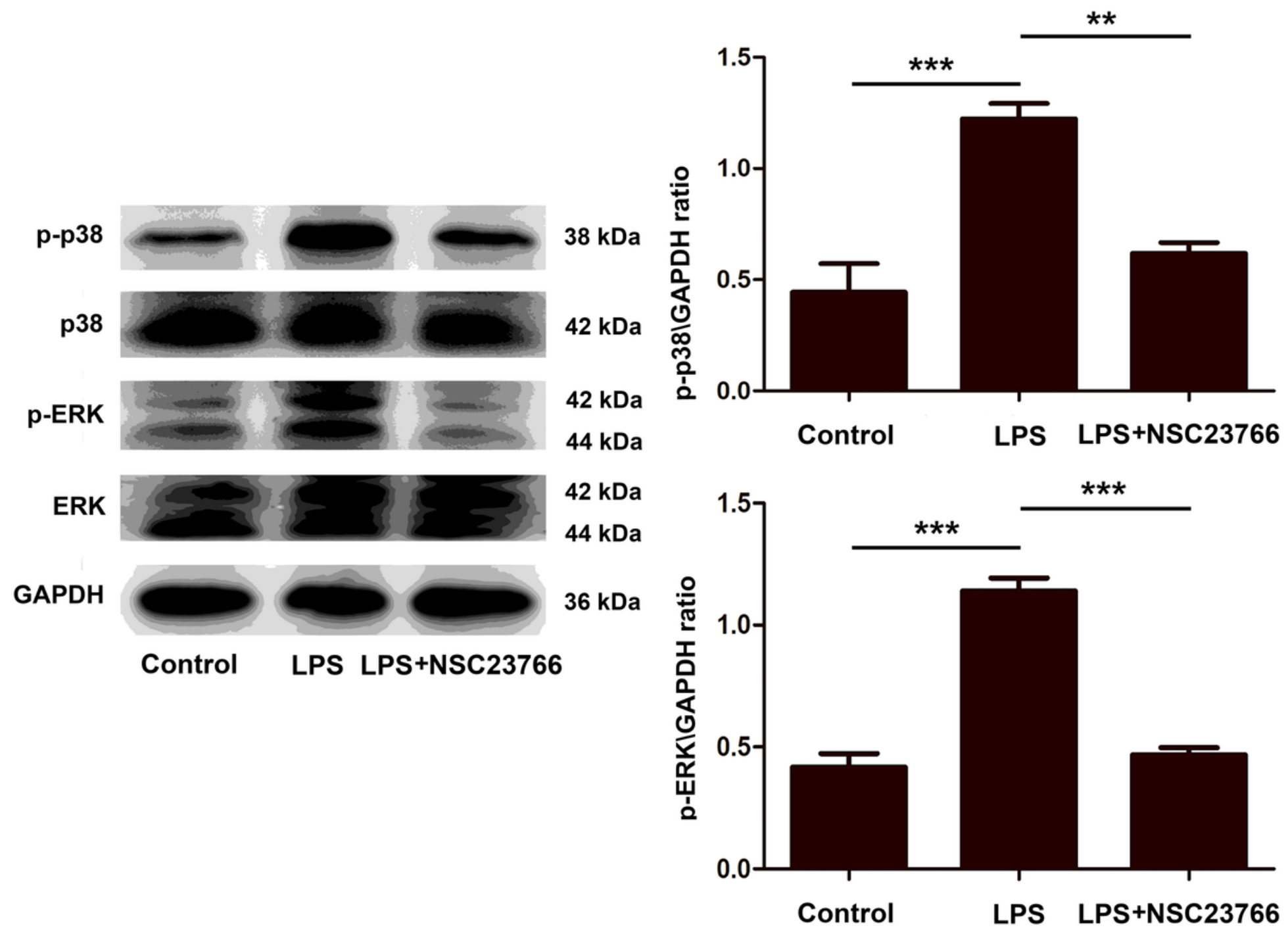

Figure 5

NSC23766 inhibited LPS-induced the phosphorylation of ERK and p38 MAPK signaling pawthway in mastitis. Western blot analysis was performed for examining ERK and p38 activities in mouse mammary gland. The results showed that NSC23766 significantly inhibited the phosphorylation of ERK and p38 MAPK signaling pawthway. The date is presented as mean $\pm S D(n=5)$. P values of $<0.05$ were considered significant. (** means $\mathrm{P}<0.01$ and $* \star \star$ means $\mathrm{P}<0.001$ ). 


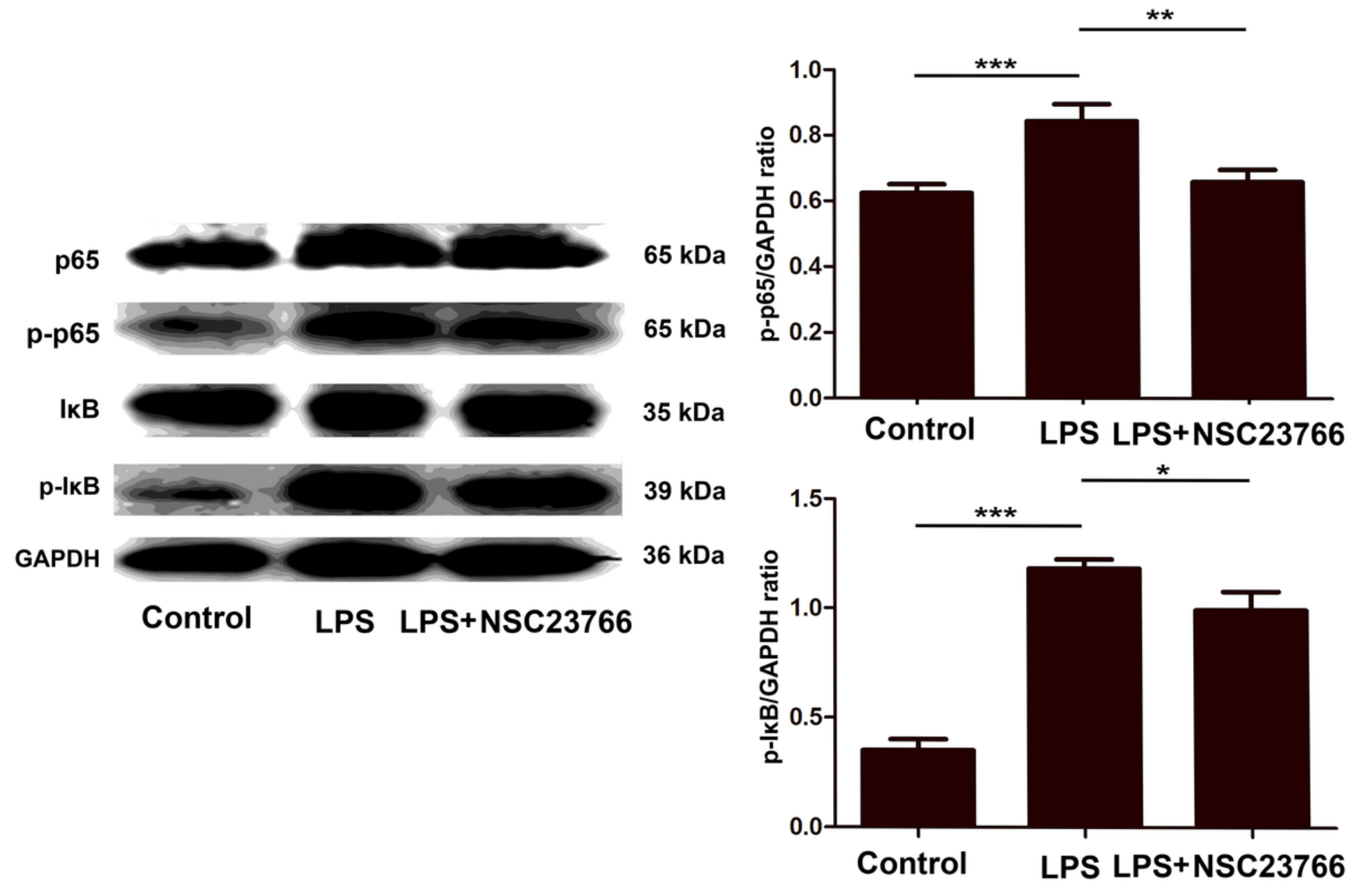

Figure 6

NSC23766 inhibited LPS-induced the phosphorylation of p65 and ІкBa NF-kB signaling pawthway in mastitis. Western blot analysis was performed for examining p65 and IKBa activities in mouse mammary gland. The results showed that NSC23766 significantly inhibited the phosphorylation of p65 and IKBa signaling pawthway. (*means $\mathrm{P}<0.05$, ** means $\mathrm{P}<0.01$ and ${ }^{* \star \star}$ means $\mathrm{P}<0.001$ ). 

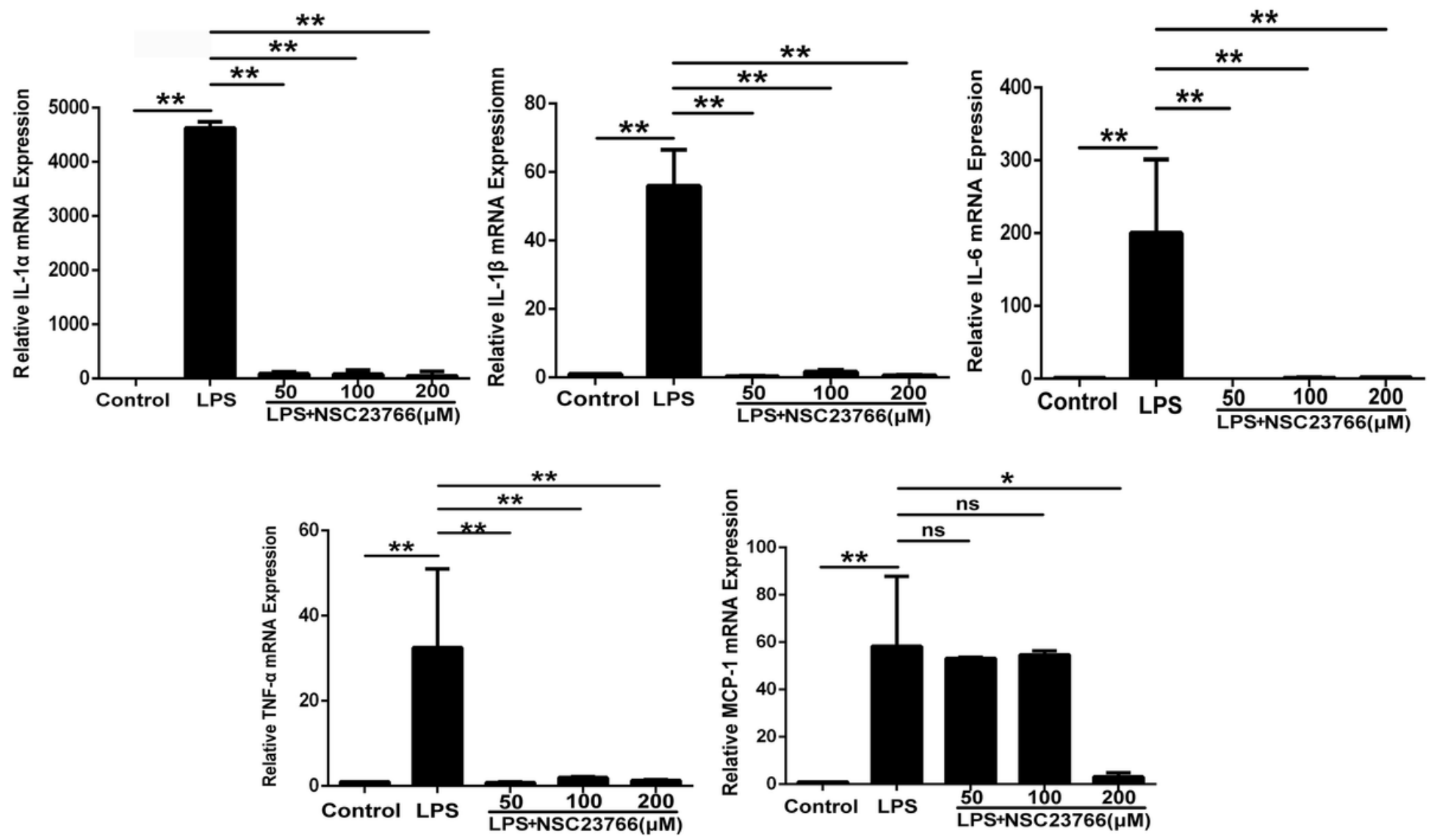

Figure 7

NSC23766 decreased the mRNA levels of IL-1a, IL-1 $\beta$, IL-6, TNF- $a$ and MCP-1 in the LPS-stimulated mouse mammary epithelial cells. The mRNA levels of IL-1 $\beta$, IL-6, TNF- $\alpha$ and MCP- 1 was measured by qRT$P C R$. The data was presented as mean \pm SD $(n=5)$. $P$ values of $<0.05$ were considered significant. (*means $\mathrm{P}<0.05$, ** means $\mathrm{P}<0.01$ and "ns"means no significant). 


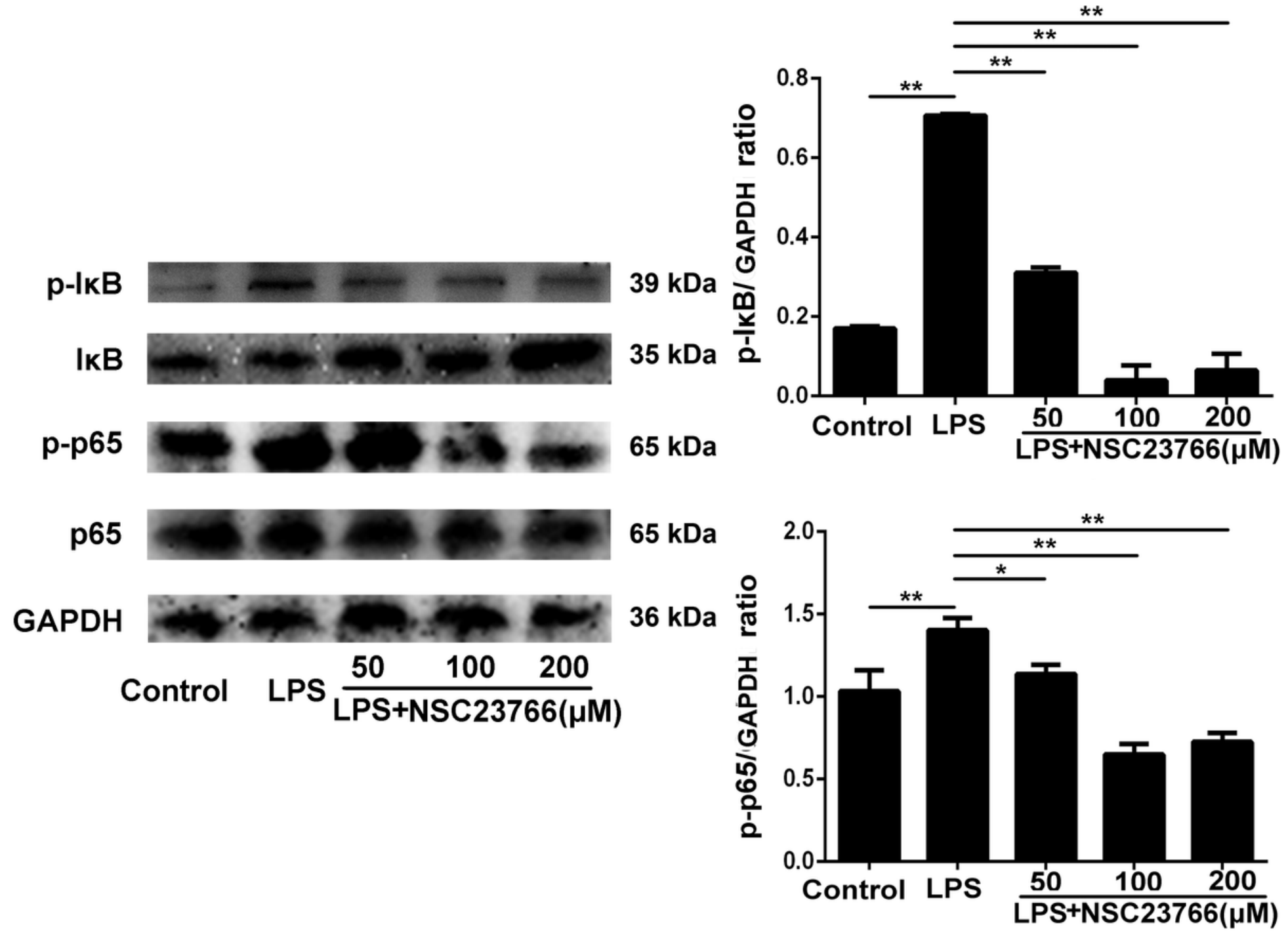

Figure 8

NSC23766 inhibited LPS-induced the phosphorylation of p65 and IKBa NF-KB signaling pawthway in mouse mammary epithelial cells. Western blot analysis was performed for examining p65 and ІкBa activities in mouse mammary epithelial cell line (EpH4-Ev). The results showed that NSC23766 significantly inhibited the phosphorylation of p65 and IKBa NF-kB signaling pawthway. ( ${ }^{*}$ means $\mathrm{P}<0.05$, ** means $\mathrm{P}<0.01)$. 